\title{
The Influence of Tourism on Rural Life in Minority Areas
}

\author{
Cuiping Zhang ${ }^{1}$, Guangming Deng ${ }^{2}$, Xiaoling $\mathbf{Y u}^{1}$ \\ ${ }^{1}$ College of Science, Guilin University of Technology, Guilin, China \\ ${ }^{2}$ The National Social Science Fund, Guilin, China \\ Email:670553212@qq.com
}

Received May 23, 2013; revised June 26, 2013; accepted July 4, 2013

Copyright (C) 2013 Cuiping Zhang et al. This is an open access article distributed under the Creative Commons Attribution License, which permits unrestricted use, distribution, and reproduction in any medium, provided the original work is properly cited.

\begin{abstract}
In this paper, taking three ethnic minority areas as an example, through a questionnaire to obtain relevant data, according to the characteristics of the ethnic minority areas, using the factor analysis method, we analyse the tourism in ethnic areas of country life with various effects. We summarize the pros and cons, avoid or minimize the adverse impacts within the maximum limits, mitigate the conflicts between the value of resource and the development, find a balance between tourism development and rural construction, realize win-win tourism development and rural construction.
\end{abstract}

Keywords: Rural Tourism; Influence; Factor Analysis

\section{Introduction}

With the rural tourism in ethnic regions being more and more popular, people also begin to focus on impact rural tourism [1] which brings to local people's living. Because of its distinctive features and functions [2], rural tourism not only meets the consumer demand for tourism [3], but also affects the developments of society [4], economy [5], environment and culture of the local [6]. In order to know how much of these four aspects' impact and what internal relationship exists [7], taking three ethnic minority areas as an example, through a questionnaire to obtain relevant data [8], according to the characteristics of the ethnic minority areas [9], using the factor analysis method [10], we analyse the tourism in ethnic areas of country life with various effects [11].

\section{The Basic Idea and Basic Method of Factor Analysis}

The idea of factor analysis stems from Charles Spearman in 1904 [12], it uses the idea of dimension reduction, starting from the original variables related to matrix inside, puts some perplexing relationship with the variable as a multivariate statistical several comprehensive factor analysis method [13].

\subsection{A Factor Model}

$$
\left\{\begin{array}{c}
X_{1}=a_{11} F_{1}+a_{12} F_{2}+\cdots+a_{1 m} F_{m}+\varepsilon_{1} \\
X_{2}=a_{21} F_{1}+a_{22} F_{2}+\cdots+a_{2 m} F_{m}+\varepsilon_{2} \\
\quad \vdots \\
X_{p}=a_{p 1} F_{1}+a_{p 2} F_{2}+\cdots+a_{p m} F_{m}+\varepsilon_{p}
\end{array}\right.
$$

Among them, $F_{1}, F_{2}, \cdots, F_{m}$ are the main factor, and respectively reflects one aspect of information unobservable latent variables; $a_{i j}$ is the factor loading coefficient, it is the $i$ index in the $j$ load factor. If an index in a factor of effect, the factor loading coefficient is high, and vice versa; $\varepsilon_{p}$ is special factor, can be ignored in the actual modeling. The cumulative contribution rate indicates the amount of information corresponding to several father-in-law factor cumulative reflect the originnal index, factor accumulation contribution rate $\geq 85 \%$ factor as the main factor number.

\subsection{The Establishment of Data Sources and Index System}

See Appendix for data sources. In this paper, through a questionnaire survey of Xijiang Miao village in Guizhou, Gongcheng Yao Autonomous County of Hongyan village and Guilin Butterfly Valley for the scenic area, collected a total of 371 effective samples. The reason for 
choosing these three sites are: Xijiang Miao village is in Leishan country which is a state-level poor country, Hongyan village is located in Gongcheng Yao Autonomous Country which is an impoverished country in Guangxi, Butterfly Valley is located in Lingui country which is an old revolutionary base area. Three minority villages have long followed the small-scale peasant economy mode of production, have embarked on the road of tourism development in support of the local government, and are representative. The questionnaire was based on the TIAS model, TIS model, Song Linfei SRSS system, combined with the specific situation in minority areas were added, from the aspects of design. The implicit index for political, economic environment, social culture, a total of 5 , the following is subdivided into 34 dominant index. The dominant index according to the $\mathrm{Li}$ Ke scale analysis method, including the 5 options, followed by "fully agree with (5)", "agreed (4)", "uncertainty (3)", "don't agree (2)", "totally disagree (1 points)". Unified data using SPSS software to do quantitative analysis, numerical value is greater, illustrate the impact of tourism on rural life more.

This study used structural questionnaire survey method to collect data. Research group designed the questionnaire, a survey, in view of the existing problems to improve the contents of the questionnaire, the interview and discussion the formal questionnaire. To carry out large-scale questionnaire survey in 2012 June-2012 year in August, in a household questionnaire, a volume, were randomly distributed 400 questionnaires, 380 were recovered, the recovery rate is $95 \%$, effective questionnaire 371 , effective rate was $92.8 \%$. Specific samples are shown in Table 1.

\subsection{Data Screening}

Factor analysis of the original data, by the principal component analysis method to extract the initial common common factors are 1 , and extract factor scale of $\times 6, \times 7$, $\times 14$ to less than 0.5 , that the three variables on the impact on the local life role of rural tourism in ethnic regions was not significant, so out of variable.

\subsection{The Reliability and Validity of Data}

After eliminating variables, doing reliability testing on 31 variables, the reliability coefficient of the most commonly used is the Cronbach alpha coefficient. Cronbach alpha coefficients ranged from 0 to 1 . The bigger the coefficient is, the higher the degree of internal consistency of the scale of each subject is, and the higher the reliability of the scale is. Applying of SPSS software and the analysis of the design of the questionnaire gives that the Cronbach alpha coefficient is 0.663 , which is in line with the requirements of the reliability level of the ques-
Table 1. Basic characteristics of samples.

\begin{tabular}{|c|c|c|c|c|c|}
\hline \multicolumn{2}{|c|}{$\begin{array}{l}\text { Demographic } \\
\text { characteristics }\end{array}$} & Frequency & Percent & \multirow{2}{*}{$\begin{array}{c}\begin{array}{c}\text { Valid } \\
\text { Percent }\end{array} \\
47.4\end{array}$} & \multirow{2}{*}{$\begin{array}{c}\begin{array}{c}\text { Cumulative } \\
\text { Percent }\end{array} \\
47.4\end{array}$} \\
\hline & Male & 176 & 47.4 & & \\
\hline & Female & 195 & 52.6 & 52.6 & 100.0 \\
\hline \multirow{5}{*}{ People } & Han & 19 & 5.1 & 5.1 & 5.1 \\
\hline & Miao & 217 & 58.5 & 58.5 & 63.6 \\
\hline & Tujia & 2 & 0.5 & 0.5 & 64.2 \\
\hline & Yao & 131 & 35.3 & 35.3 & 99.5 \\
\hline & Zhuang & 2 & 0.5 & 0.5 & 100.0 \\
\hline \multirow{3}{*}{$\begin{array}{l}\text { Household } \\
\text { register }\end{array}$} & Local people & 321 & 86.5 & 86.5 & 86.5 \\
\hline & Outsiders & 50 & 13.5 & 13.5 & 100.0 \\
\hline & $\begin{array}{l}\text { Less than } 20 \\
\text { years old }\end{array}$ & 18 & 4.9 & 4.9 & 4.9 \\
\hline \multirow{3}{*}{ Age } & 21 - 39 years old & 136 & 36.7 & 36.7 & 41.6 \\
\hline & $40-59$ years old & 172 & 46.4 & 46.4 & 88.0 \\
\hline & $\begin{array}{l}\text { Above } 60 \\
\text { years old }\end{array}$ & 45 & 12.1 & 12.1 & 100.0 \\
\hline \multirow{3}{*}{ Work } & $\begin{array}{l}\text { Not to } \\
\text { participate in the } \\
\text { tourism service }\end{array}$ & 130 & 35.0 & 35.0 & 35.0 \\
\hline & $\begin{array}{l}\text { Participation in } \\
\text { tourism service }\end{array}$ & 223 & 60.1 & 60.1 & 95.1 \\
\hline & Other work & 18 & 4.9 & 4.9 & 100.0 \\
\hline \multirow{5}{*}{$\begin{array}{l}\text { Cultural } \\
\text { degree }\end{array}$} & $\begin{array}{l}\text { Didn't go to } \\
\text { school. }\end{array}$ & 54 & 14.6 & 14.6 & 78.7 \\
\hline & Primary school & 79 & 21.3 & 21.3 & 100.0 \\
\hline & $\begin{array}{c}\text { Junior middle } \\
\text { school }\end{array}$ & 163 & 43.9 & 43.9 & 43.9 \\
\hline & $\begin{array}{l}\text { High school } \\
\text { (secondary } \\
\text { school) }\end{array}$ & 72 & 19.4 & 19.4 & 64.2 \\
\hline & $\begin{array}{l}\text { University or } \\
\text { above }\end{array}$ & 3 & 0.8 & 0.8 & 44.7 \\
\hline \multirow{4}{*}{$\begin{array}{l}\text { The total } \\
\text { family } \\
\text { income }\end{array}$} & $\begin{array}{c}\text { More than } \\
25,000\end{array}$ & 75 & 20.2 & 20.2 & 48.2 \\
\hline & $15,000-25,000$ & 104 & 28.0 & 28.0 & 28.0 \\
\hline & $5000-15,000$ & 145 & 39.1 & 39.1 & 87.3 \\
\hline & Less than 5000 & 47 & 12.7 & 12.7 & 100.0 \\
\hline \multirow{4}{*}{$\begin{array}{l}\text { Source of } \\
\text { family } \\
\text { income }\end{array}$} & $\begin{array}{l}\text { Not from } \\
\text { tourism }\end{array}$ & 76 & 20.5 & 20.5 & 20.5 \\
\hline & $\begin{array}{l}\text { Less from } \\
\text { tourism }\end{array}$ & 61 & 16.4 & 16.4 & 65.5 \\
\hline & $\begin{array}{c}\text { From the part of } \\
\text { Tourism }\end{array}$ & 106 & 28.6 & 28.6 & 49.1 \\
\hline & $\begin{array}{l}\text { Mainly from } \\
\text { tourism }\end{array}$ & 128 & 34.5 & 34.5 & 100.0 \\
\hline
\end{tabular}


tionnaire. Validity is a measure of the accuracy of the results. Validity is the validity of data scale, the scale can accurately, really, objectively test attributes of things. Usually the structural validity of the questionnaire is used to study the validity of the questionnaire. Construct validity refers to the concept of measuring tool measureing theory or a special degree. This study uses confirmatory factor analysis method to examine the construct validity of extracting common factor, the method of principal component, factor rotation by the varimax rotation. Through the rotation of variables, we find that all the factors loading are greater than 0.5 , so the validity of scale is in line with the requirements.

\section{Factor Analysis}

\subsection{Factor Analysis}

Factor analysis of the 31 variables using the SPSS19.0, the KMO value is 0.746 , Bartlett value is 2320.405 , and Sig is 0 (see Table 2). These mean that the data is suitable for factor analysis. And the four groups of indicators of the corresponding factor analysis, 19 factors were extracted. The political aspect extracted 3 common factors accumulated explanatory variables into $78.164 \%$, economic aspects of the sample of 4 common factor accumulative explanatory variables into $75.869 \%$, environmental sample of 4 common factor accumulative explanatory variables into $85.151 \%$, culture extract 8 common factor accumulative explanatory variables into $71.902 \%$.

\subsection{The Framework of Indicator System and Weight Determination}

Through the index search, classified, and using SPSS19.0 analysis and selection of indicators, 19 factors are eventually extracted, we rename and arrange those factors in Table 3.

In the naming of the 19 factors, the weight of 19 indicators, we use the principal component analysis method. The ratio of each factor's contribution rate and accumulated contribution rate is considered as the weight of the factors. Because tourism on rural political, economic, environmental, cultural influences has an equally important position, the political, economic, environmental, cultural four index weight is set to be the same. This can

Table 2. KMO tests and Bartlett.

\begin{tabular}{ccc}
\hline Sampling enough of Kaiser-Meyer-Olkin metric. & 0.746 \\
\hline \multirow{3}{*}{ Approximate chi-square } & 2320.405 \\
Sphericity Test Bartlett & df & 465 \\
& Sig. & 0.000 \\
\hline
\end{tabular}

Table 3. The nomenclature and factor contribution rate.

\begin{tabular}{|c|c|c|c|}
\hline Index & Factor & \multicolumn{2}{|c|}{ Loading } \\
\hline \multirow{4}{*}{$\begin{array}{l}\text { Politics } \\
\text { Influence }\end{array}$} & Factor & $\begin{array}{c}\text { Factor } \\
\text { load }\end{array}$ & $\begin{array}{c}\text { Factor } \\
\text { contribution }\end{array}$ \\
\hline & Cadre corruption $F_{1}$ & 0.975 & 41.654 \\
\hline & Policy changes $F_{2}$ & 0.865 & 22.939 \\
\hline & Understand the policy $F_{3}$ & 0.730 & 13.571 \\
\hline \multirow{4}{*}{$\begin{array}{l}\text { Economics } \\
\text { Influence }\end{array}$} & Poverty gap $F_{4}$ & 0.997 & 31.147 \\
\hline & Rent prices $F_{5}$ & 0.969 & 19.395 \\
\hline & The land problem $F_{6}$ & 0.726 & 14.079 \\
\hline & $\begin{array}{c}\text { To increase the } \\
\text { income of farmers } F_{7}\end{array}$ & 0.689 & 11.249 \\
\hline \multirow{4}{*}{$\begin{array}{c}\text { Environmental } \\
\text { Science } \\
\text { Influence }\end{array}$} & Sanitary condition $F_{8}$ & 0.976 & 26.765 \\
\hline & Infrastructure $F_{9}$ & 0.960 & 23.142 \\
\hline & Traffic jam $\quad F_{10}$ & 0.918 & 18.369 \\
\hline & $\begin{array}{l}\text { The ecological } \\
\text { environment } F_{11}\end{array}$ & 0.773 & 16.876 \\
\hline \multirow{8}{*}{$\begin{array}{l}\text { Culture } \\
\text { Influence }\end{array}$} & $\begin{array}{l}\text { Outdated customs and } \\
\text { bad habits } F_{12}\end{array}$ & 0.896 & 14.314 \\
\hline & External conflict $F_{13}$ & 0.889 & 11.590 \\
\hline & Family and marriage $F_{14}$ & 0.857 & 9.755 \\
\hline & Religious conflict $F_{15}$ & 0.812 & 7.944 \\
\hline & Crime rate $F_{16}$ & 0.810 & 7.653 \\
\hline & $\begin{array}{l}\text { Scienceandtechnology } \\
\text { information } F_{17}\end{array}$ & 0.739 & 7.504 \\
\hline & Neighborhood disputes $F_{18}$ & 0.702 & 6.734 \\
\hline & Moral standards $F_{19}$ & 0.680 & 6.409 \\
\hline
\end{tabular}

reflect that the tourism has the same important position on the effect of four aspects of the country, but also to political, tourism to the country influence of economy, environment, coordination of culture, according to the index system of factors and their weights, the evaluation of tourism on rural effect is established, various weight is shown in Table 4.

It is seen from Table 4, weight three indicators reflect the impact of tourism on the rural local life, cadres corruption factor, the gap between rich and poor sanitary condition factor, weighting factor is high, up to 0.5329 , $0.4105,0.3143$. With the development of the local tourism, the local economy income increases, but due to various reasons, some people get a lot of interest, while others have little interest, increasing the income inequality, the growing gap between rich and poor. At the same time, because of economic development, the cadre of available resources is relatively more, also makes the corruption becomes more serious. In the process of tourism development, the population increase, because of, 
Table 4. Effect evaluation index system of rural tourism.

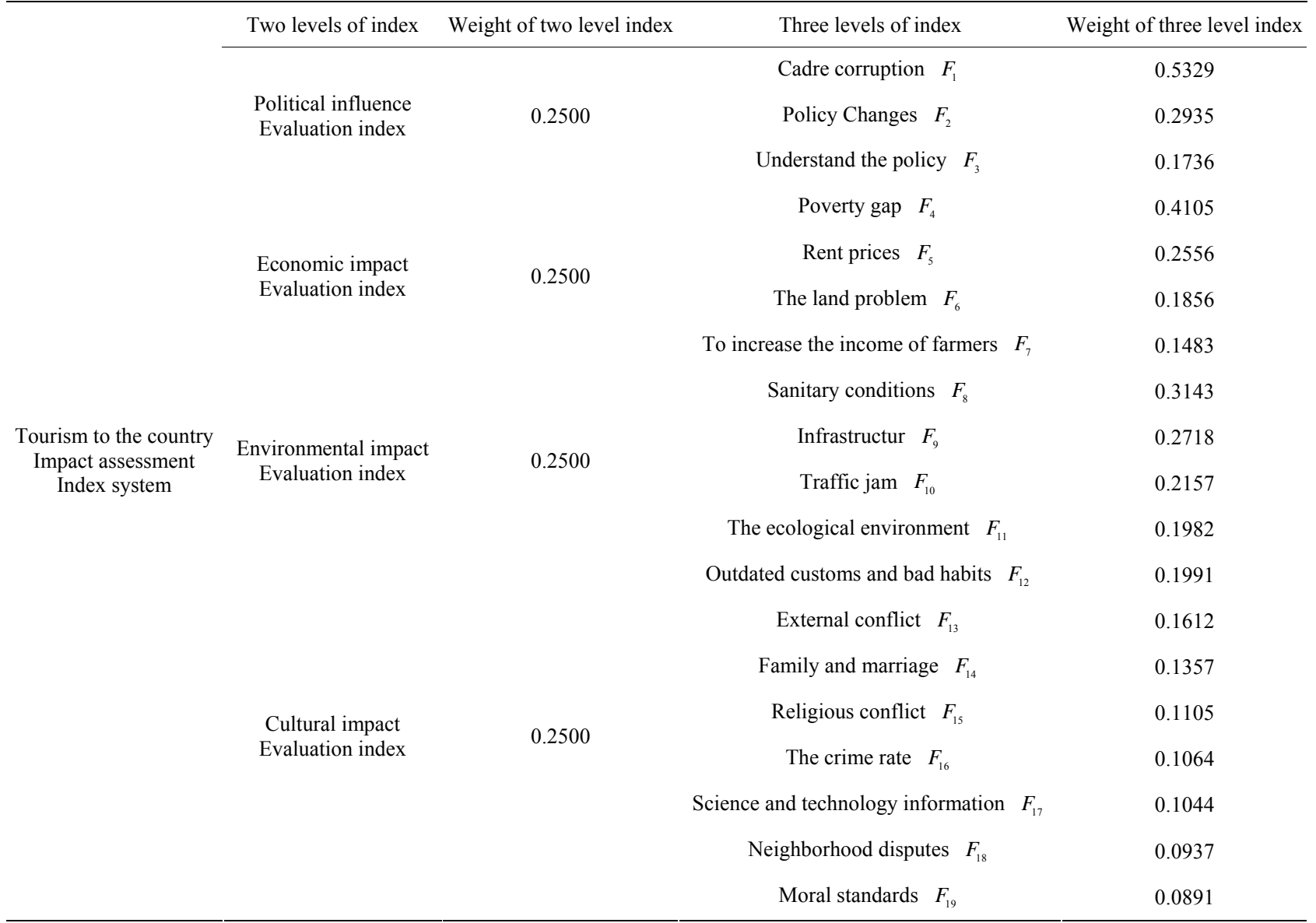

the local environment has also been greatly affected. Other factors also have a different impact of tourism on the. In general, the score weights to individual factors still have bigger difference, this also shows, travel or have had a considerable effect on some local factors.

\section{Summary}

Everything has two sides. In order to develop the rural tourism better, increase the positive impact of tourism on the local, to reduce the negative influence, we should make full use of the macro-adjusting role of government so that more people can enjoy the comprehensive benefits of tourism. While increasing the tourism economy, the government should also carry out the supervision, to create civilized and harmonious cultural atmosphere, strengthen the health construction of the environment, to promote the local economy develop steadily.

\section{REFERENCES}

[1] M. X. Wang and S. P. Xu, "Establish a Diversified Contradictions Mechanism to Promote the Construction of Efficient and Ecological Economic Region of the Dongy- ing City," Journal of Party School of Shengli Oilfield, Vol. 1, No. 4, 2011, pp. 91-97.

[2] C. Rong, "The Influence of the Development of Rural Tourism on the Rural Economy," Modern Economic Information, Vol. 1, No. 4, 2011, p. 243.

[3] J. Wei and D. Xue, "Influence of Rural Tourism on the Rural Economy and Sustainable Development," Jiangxi Journal of Agricultural Sciences, Vol. 1, No. 4, 2010, pp. 150-152.

[4] Group of Stone, "The Impact of Tourism on Chinese Rural Culture Research Review," Journal of Ningbo University (Humanities Science Edition), Vol. 1, No. 4, 2011, pp. 22-25.

[5] R. Q. Shi and J. Hua, "Influence of Rural Tourism to Dangchang County Yin Ping Qiang Village Culture and Countermeasures Analysis," China, Vol. 2, No. 2, 2011, p. 31.

[6] Y. Liu, "Case of Ethnic Communities Social Impact of Rural Tourism in Sichuan Jiaju Tibetan Area Survey," Ningxia Social Science, Vol. 1, No. 6, 2007, pp. 77-79.

[7] H. Zhang and S. Gong, "Study on Effect of Rural Tourism Development in the Construction of Harmonious Jiangxi and Countermeasures," Network Wealth, Vol. 1, No. 5, 2008, pp. 91-93.

[8] T. Liu and F. Y. Xu, "The Rural Community Participation in Tourism in the Interest Conflict and Coordination," 
Social Scientists, Vol. 1, No. 5, 2010, pp. 91-94.

[9] X. Y. Shi, "Basic Social Contradictions and Disputes Resolving Mechanism Study in South Guangxi H County as an Example," Central South University, 2011.

[10] J. Zhu, "Construction of Coordinating the Interests Contradiction and Harmonious Society," Beijing Jiaotong University, 2008.

[11] X. J. Liu, "The Contradiction of Rural Public Domain from the Perspective of a Harmonious Society and the Solution," Huazhong Agricultural University, 2010.

[12] X. M. Zhang, "In the Construction of Harmonious Society of Social Contradictions to Resolve," Anhui University, 2011.

[13] J. N. Wang, "Impact of Rural Tourism on the Rural Community," Zhejiang University, 2010. 